\title{
Ultraviolet Induction of Chromosome Transfer by Autonomous Sex Factors in Escherichia coli
}

\author{
By Z. EVENCHIK* \\ Medical Research Council, Microbial Genetics Research Unit, \\ Hammersmith Hospital, Ducane Road, London, W. 12 \\ K. A. STACEY \\ School of Biological Sciences, University of Sussex, Falmer, Brighton, Sussex \\ AND W. HAYES $\dagger$ \\ Medical Research Council, Microbial Genetics Research Unit
}

(Accepted for publication 19 November 1968)

\section{SUMMARY}

Ultraviolet irradiation of Escherichia coli $\mathrm{K} \mathrm{I} 2$ bacteria, carrying an autonomous $F$ factor or an F-prime factor, enhances the fertility of the population by increasing the number of cells which can transfer the bacterial chromosome. In contrast, under similar conditions the fertility of irradiated Hfr populations falls in proportion to the survivors. Following irradiation, the effect begins to develop after about $30 \mathrm{~min}$. incubation in broth at $37^{\circ}$, reaches a peak at about $90 \mathrm{~min}$., and thereafter slowly declines. The effect develops with similar kinetics during post-irradiation incubation in minimal medium as in broth, provided the bacteria have been minimal-grown; in the case of broth-grown cells, appearance of the effect in minimal medium is greatly delayed. A comparison of the kinetics of the effect with the growth of the population as a whole shows that the u.v.-induced donor state is not inheritable. Mitomycin C, which resembles u.v. radiation in producing DNA damage repairable by a mechanism involving excision of single-stranded fragments, also induces new donor bacteria. Other agents such as X-rays and methyl methansulphonate (MMS) do not stimulate the production of new donors but may enhance the recombination frequency since cells killed by them may continue to act as chromosome donors. The effect is not shown either by $u v r$ mutants (unable to excise thymine dimers) or by rec mutants (unable to mediate recombination) which carry an F-prime factor. A possible mechanism is suggested whereby the excision of single-stranded fragments of the bacterial chromosome, during the repair of u.v. damage, facilitates pairing with homologous regions of the complementary sex factor strand. A recombination event, mediated by breakage and covalent bonding, then joins a free end of the excised DNA strand to the paired sex factor strand. In this way, recombination connects sex factor and chromosome by only a single strand instead of by the two strands which normally leads to insertion and the formation of an Hfr chromosome. It is postulated that such a structure can be transferred at conjugation, but is incapable of more than one cycle of replication.

* Present address: Israeli Institute for Biological Research, Ness-Ziona, P.O. Box 19, Israel.

$\dagger$ Present address: Department of Molecular Biology, University of Edinburgh, Mayfield Road, Edinburgh 9, Scotland. 


\section{INTRODUCTION}

Stimulation of recombinant formation in Escherichia coli $\mathrm{K}$ I 2 crosses by ultraviolet (u.v.) irradiation of the parental bacteria was first reported by Haas, Wyss \& Stone (1948). Following the discovery of sexual differentiation, Hayes (1952) found that the effect is exclusively due to an increase in the fertility of the donor ( $\mathrm{F}^{+}$male) population; irradiation of the recipient ( $\mathrm{F}^{-}$female) parental bacteria decreases the number of recombinants in proportion to the survivors. Subsequent analysis showed that u.v. irradiation fails to increase the fertility of Hfr male bacteria, which is presumably already maximal, the number of recombinants falling with increasing dosage, in parallel with the viable count. The effect is photo-reactivable and requires incubation of the broth-grown irradiated $\mathrm{F}^{+}$bacteria in a rich medium for its development (Hayes, I953). With the advent of methods of mating in liquid media, the induction by u.v. irradiation of as high as a 50-fold increase in the total number of recombinants can be achieved under optimal conditions, but this enhanced ability to generate recombinants is not inherited by the descendants of the induced $\mathrm{F}^{+}$bacteria (Hayes, 1960).

In this paper we redefine the phenomenon as the induction by u.v. radiation of new chromosome donors, in bacterial populations which carry an autonomous sex factor; this induction is reflected in an increase in the absolute number of recombinants gener ated, as opposed to an increase in the frequency of recombination (number of recombinants/100 donor bacteria) which can be due to other causes, as we shall show. We also postulate that this induction of new donors is due to an abnormal mechanism of incorporation of the sex factor into the bacterial chromosome. We present evidence that this incorporation depends on excision of single-stranded fragments of DNA during repair of irradiation damage, as well as on an act of recombination, resulting in the formation of a transmissible structure which is not inheritable and may be lethal. A model for this structure is proposed and some experiments in support of it are described.

\section{METHODS}

Strains. All Escherichia coli strains were K 12 derivatives; only mutant characters are designated below. The $\mathrm{F}^{+}$, intermediate male and Hfr strains used in most comparative irradiation studies were isogenic, as follows:

$\mathrm{F}^{+}$: W 1655. $m e t^{-\lambda} \lambda-\lambda-r$ (Lederberg \& Lederberg, 1953).

Intermediate male: W I655. $\mathrm{F}^{-}$infected with an F-lac ${ }^{+}$factor derived from $\mathrm{Hfr}$. B I (Scaife \& Gross, 1963; Broda, Beckwith \& Scaife, 1964; Broda, 1967).

Hfr: Hfr.BI, derived from w $1655 . \mathrm{F}^{+}$, transferring the proB locus as the first chromosomal marker and lac as the last (Broda, 1967), was used as a control strain in many experiments.

Hfr.H.gal ${ }^{-}$prototroph, kindly provided by Dr J. Shapiro, was used as recipient for transduction of the $u v r B$ locus which is jointly transducible with the gal region by phage $\mathrm{P} I$.

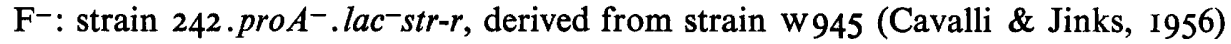
by recombination, was usually used as recipient in crosses, selection being made for pro $^{+}$recombinants.

W 1655. met $^{-}$(Lederberg \& Lederberg, 1953).

w I655. met thy $^{-}$isolated by selecting for thymine requirement by the procedure of Stacey \& Simson (1965). 
w I655.uvr- isolated by Miss C. Atkinson by selection with phage T I 'inactivated' with u.v. light (Howard-Flanders \& Theriot, 1962).

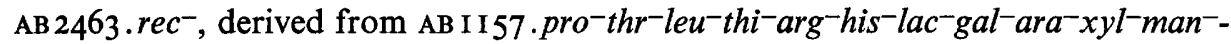
$s t r-r$ (Howard-Flanders \& Theriot, I966).

$\mathrm{AB} 1886 . u v r A ; \mathrm{AB} 1885 . u v r B^{-}$: both derived from AB I 157 (Howard-Flanders, Boyce \& Theriot, 1966).

J6-2.pro-try-his-lac-str-r (Clowes \& Rowley, 1954).

In addition, use was made of an intermediate male strain [JW-6. A I .thr-leu- thi-lac ${ }^{-}$ $\left(\mathrm{F}-\mathrm{lac}^{-}\right)$] isolated by $\mathrm{Mr} \mathrm{J}$. Walpole as resistant to u.v. light and also, apparently, recombination-defective.

Media. All experiments were performed in nutrient ' $L$ ' broth (Lennox, 1955) or in M9 minimal medium supplemented with glucose and appropriate amino acids.

Platings for viable counts were made on nutrient agar and counted after overnight incubation at $37^{\circ}$. Recombinants were scored after $48 \mathrm{hr}$ at $37^{\circ}$ on $\mathrm{Mg}$ minimal-glucose agar, supplemented according to the required selection.

Buffer was $\mathrm{M} / \mathbf{1} 5$ phosphate buffer at $\mathrm{pH} 7 \cdot 2$.

Concentrated broth: ' $L$ ' broth concentrated $\times$ Io.

Methods. Bacteria were grown and crossed in liquid medium, in screw-capped bottles attached to the periphery of a $33 \mathrm{rev} . / \mathrm{min}$. turntable in a $37^{\circ} \mathrm{room}$.

Irradiation. All bacteria were irradiated after washing by filtration on a Millipore filter and resuspending in buffer.

Source of u.v. radiation: a low-pressure Hanovia 15 W. germicidal lamp used at a distance of $50 \mathrm{~cm}$., giving a dose of about $4 \mathrm{ergs} / \mathrm{mm} .{ }^{2} / \mathrm{sec}$.

Source of $X$-rays: a Phillips apparatus, yielding $\mathrm{I} \cdot 3 \mathrm{Krad} . / \mathrm{min}$. was used. X-irradiation was done in buffer, both in the presence and in the absence of oxygen; although the viable count fell more rapidly in the presence of oxygen, there was no differential effect on chromosomal mobilization.

Recombination frequency is calculated as the number of recombinants per 100 male bacteria in the initial mating mixture. In most experiments the ratio male:female bacteria in the mating mixture was $\mathrm{I}: \mathrm{IO}$.

\section{RESULTS}

\section{The phenomenon}

The effect of u.v. radiation on the fertility of isogenic $\mathrm{F}^{+}$, intermediate male $\left(\mathrm{F}-\mathrm{lac}^{+}\right)$ and Hfr cultures is shown, in typical experiments, in Table I. Instead of the decrease found in the total number of recombinants when the Hfr strain is irradiated, the total numbers of recombinants by irradiated $\mathrm{F}^{+}$and intermediate males is markedly increased. In these latter cases, therefore, bacteria which carry an autonomous sex factor, but do not yield recombinants, are induced to do so by u.v. irradiation. In addition, the fact that the increase in the recombination frequency is greater than the increase in the absolute number of recombinants, suggests that, unlike the case of $\mathrm{Hfr}$ bacteria in which the recombination frequency remains constant, at least a proportion of non-surviving male bacteria can generate recombinants. Although the absolute number of recombinants given by a u.v.-induced intermediate (F-prime) population is much greater than in the case of $\mathrm{F}^{+}$populations, the relative increase in both total number and frequency of recombinants is markedly smaller. This, presumably, is 
because the irradiated intermediate male population yields a number of recombinants approximately equivalent to that observed for a corresponding Hfr populationvirtually every conjugation event results in chromosome transfer, so that there is little room for further increase. It is worth noting that, in the case of intermediate males, the ratio of inheritance of distal $\left(\right.$ his $\left.^{+}\right)$and proximal $\left(\right.$pro $\left.^{+}\right)$markers does not differ significantly before and after u.v. treatment.

Table I. A comparison of the effect of u.v. irradiation on the fertility of isogenic populations of $\mathrm{F}^{+}$, intermediate male and $\mathrm{Hfr}$ bacteria

One tenth vol. overnight broth cultures of $\mathrm{F}^{+}$, intermediate male (F-lac $\left.{ }^{+}\right)$and $\mathrm{Hfr}$ male derivatives of $E$. coli $\mathrm{K} \mathrm{I} 2$ strain W 1655 , as well as of the $\mathrm{F}^{-}$strain 242 , were transferred to fresh broth at $37^{\circ}$ and incubated on a rotor. After $\mathrm{I} \frac{1}{2} \mathrm{hr}$ the male culture was washed, resuspended to vol. in buffer, diluted 1 in 10 and irradiated with u.v. radiation to $40-60 \%$ survival. One tenth vol. conc. broth was added, the suspension incubated at $37^{\circ}$ for $\mathrm{I}$ hr and then mated with the strain $242 . \mathrm{F}^{-}$suspension for $45 \mathrm{~min}$. at $37^{\circ}$. Samples were finally diluted and plated for pro $^{+}$recombinants. In each case the sample of the washed suspension of male bacteria, before irradiation, was enriched with conc. broth and immediately mated with the $\mathbf{F}^{-}$bacteria as control.

Type of

male

bacterium

$\mathrm{F}^{+}$

F-lac ${ }^{+}$

Hfr
Total number of recombinants per $\mathrm{ml}$.

$\begin{array}{ccc}\text { Before u.v. } & \text { After u.v. } & \text { Increase } \\ 8 \times 10^{8} & 1.6 \times 10^{5} & \times 20 \\ 8 \times 10^{5} & 4.0 \times 10^{6} & \times 5 \\ 3 \times 10^{7} & 1.8 \times 10^{7} & \times 0.6\end{array}$

Recombination frequency

$\begin{array}{ccc}\text { Before u.v. } & \text { After u.v. } & \text { Increase } \\ 1 \cdot 7 \times 10^{-2} & 6 \times 10^{-1} & \times 35 \\ 5 & 60 & \times 12 \\ 40 & 40 & \times 1 \cdot 0\end{array}$

The absolute increase in numbers of recombinants generated by irradiated $\mathrm{F}^{+}$and intermediate (F-lac ${ }^{+}$) bacteria could be due to: (I) an enhanced efficiency of conjugation; (2) a greater probability that cells already having an integrated sex factor will transfer their chromosome on conjugation; (3) an increased efficiency of incorporation of transferred segments into recombinant chromosomes; (4) an increase in the frequency of sex factor integration into the chromosome.

The first three possibilities are unlikely since neither the transfer of an autonomous sex factor such as F-lac ${ }^{+}$by intermediate male strains, nor the number of recombinants generated by Hfr strains, are increased by irradiation (see Fig. r). The fourth possibility was therefore investigated in more detail.

\section{The effect of u.v. dosage}

The effect of increasing u.v. dosage on the number of recombinants, and on the recombination frequency, is demonstrated in Fig. $\mathrm{r}$. In the case of both $\mathrm{F}^{+}$and intermediate males, the total number of recombinants begins to rise at a u.v. dose which scarcely affects survival ( $>95 \%$ ) and continues to do so until a survival level of about $30 \%$ is reached. Thereafter the killing effect of increasing u.v. dosage dominates the curve so that the total number of recombinants begins to fall at about the same rate as the number of survivors-the recombination frequency reaches a plateau. There are two possible explanations for the plateau. One is that the probability of the effect occurring increases with dose up to the point where the maximal amount of u.v. damage compatible with survival is sustained; thereafter new donors continue to be formed but a decreasing proportion of these can express themselves. Alternatively, the plateau could represent the dose at which the maximal possible number of chromosomal 
donors have been induced and that, with increasing dosage, these decline at the same rate as the population at large, as in the case of Hfr bacteria (Fig. I C). Since, as we shall see, the development of the effect depends on u.v. damage while the evidence suggests that induced donor cells may be inviable, we favour the first explanation of the dose effect curve and will discuss it again later.
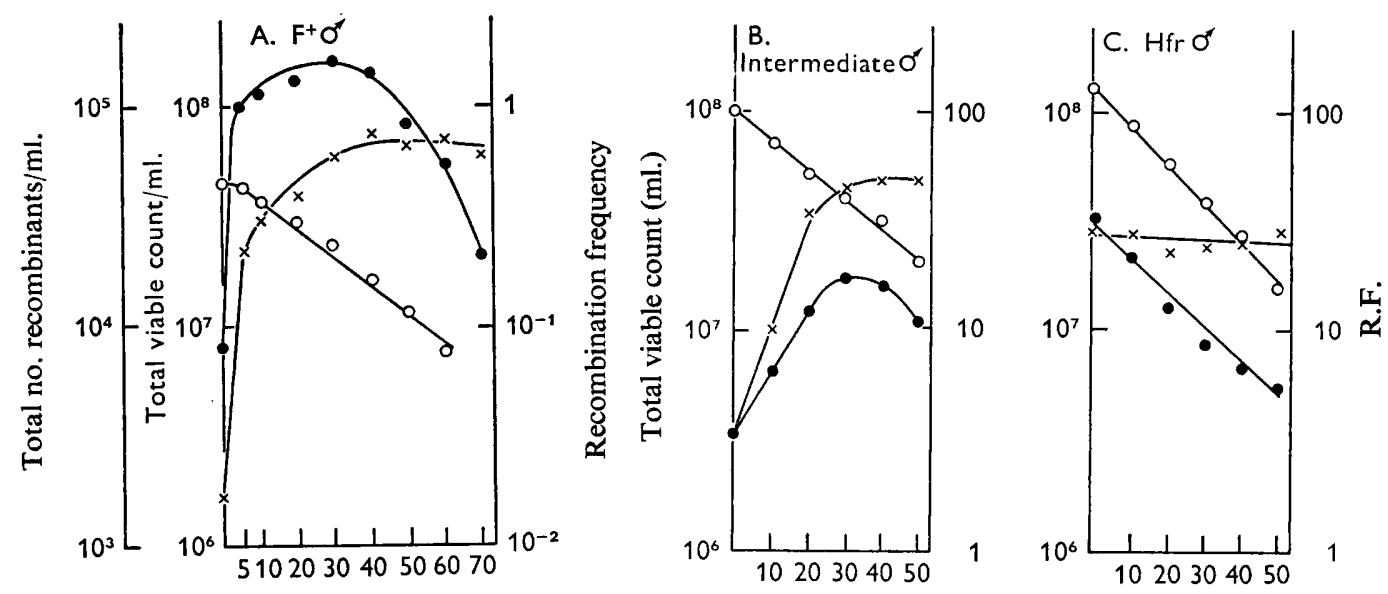

Time of irradiation (sec.)

Fig. I. Dose-response curves of total recombinants, recombination frequency and survival for three types of male bacteria irradiated with u.v. radiation. $A=F^{+}$male $\left(\mathrm{W} \mathrm{I} 655 . \mathrm{F}^{+}\right) . \mathrm{B}=$ Intermediate male (W I655(F-lac $\left.{ }^{+}\right)$) ex HfrBI. $\mathrm{C}=\mathrm{Hfr}$ male (HfrBI ex W I655. $\mathrm{F}^{+}$). In all cases the experiments were performed as described in Table I, except that the u.v. dose used was varied. In A, a different u.v. lamp was used. - - Total pro ${ }^{+}$recombinants; $\bigcirc-O$, total viable count; $x-\times$, recombination frequency $(\mathrm{RF})$.

\section{Kinetics of development of the effect}

In this section we will study the development of the effect as a function of time of incubation in broth (or other media) following u.v. irradiation. The rise with time in the number of recombinants issuing from an irradiated $\mathrm{F}^{+}$strain is shown in Fig. 2. The total number of recombinants appears to begin to rise immediately after incubation, reaches a peak at about $\mathrm{I} \frac{1}{2} \mathrm{hr}$ later and then slowly declines. The total viable count begins to increase exponentially after a lag of about $\mathrm{I} \mathrm{hr}$. In experiments with intermediate male strains, similar kinetic curves are obtained.

There are two important points about the nature of these curves. The first is whether Fig. 2 reveals the true kinetics of development of the effect following incubation in broth, since the times indicated are those at which the samples were taken for mating, which involves a further period of $45 \mathrm{~min}$. in broth. It is therefore possible that the effect is not already manifest in the early samples but develops later, during the mating period. In order to distinguish these possibilities, samples of $\mathrm{F}^{+}$bacteria, incubated in broth for various times after irradiation (as before), were mated with female bacteria for 15 and $30 \mathrm{~min}$. as well as for $45 \mathrm{~min}$. It turned out that the samples removed immediately after resuspension of the irradiated bacteria in broth, and mated for only I 5 min., gave the same number of recombinants as the unirradiated control. When the mating time was increased to $30 \mathrm{~min}$., this sample showed a small increase in the number of recombinants. This same small increase was given by the sample removed 
at $15 \mathrm{~min}$. and mated for 15 min., the total time of incubation in broth again being $30 \mathrm{~min}$. Thus the effect is not initiated immediately but only after $30 \mathrm{~min}$. in broth, and can develop in the mating mixture.

The second point concerns the relationship of the effect to division of $\mathrm{F}^{+}$cells. Figure 2 appears to show that most of the new donors have been induced before the irradiated population begins to divide at about $\mathrm{I} \mathrm{hr}$ after incubation. This would imply that the majority of new donors cannot multiply as such for if they did the number of donors, and therefore of recombinants, would double with the population

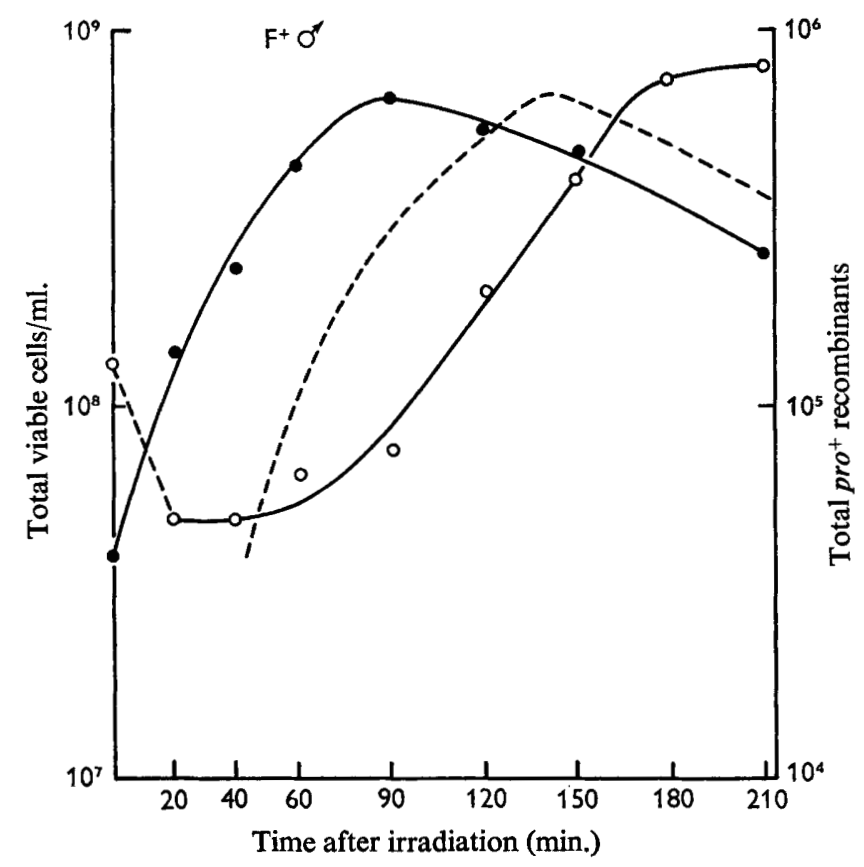

Fig. 2. The kinetics of development of the u.v. effect in an $\mathrm{F}^{+}$strain. The experiment was performed as described in the legend to Table I, except that samples of irradiated $\mathrm{F}^{+}$suspension were removed for mating and viable count at intervals after incubation in broth at $37^{\circ}$. Survival immediately after irradiation $=40 \% .-$, Total pro ${ }^{+}$recombinants; $\mathrm{O}-\mathrm{O}$, total viable count.

as a whole. However, since the effect has now been shown to continue to develop during the $45 \mathrm{~min}$. mating period in broth, the samples from which the recombinant curve is constructed should really be transposed $45 \mathrm{~min}$. to the right in Fig. 2, as indicated by the interrupted line. When this is done, the rise in the number of recombinants appears to coincide with the increase in the viable count over most of the growth cycle, so that the latter part of the rise could be due to multiplication of induced donors, curtailed only by entry into the stationary phase.

There are three good reasons for believing that this interpretation is incorrect and that, in fact, induced donors do not multiply. First, viable counts show that exponentially growing $\mathrm{F}^{+}$bacteria stop multiplying when mixed in a $\mathrm{I}$ in $\mathrm{Io}$ minority with female bacteria under the conditions of mating employed, so that the number of recombinants is properly related to the number of $\mathrm{F}^{+}$bacteria at the time of sampling 
and not $45 \mathrm{~min}$. later. Secondly, minimal-grown bacteria, after irradiation and incubation in minimal medium, may develop the maximal effect in the absence of any cellular increase (see below). Thirdly, samples of irradiated $\mathrm{F}^{+}$bacteria taken after I hr incubation in broth, diluted two-, four- and eightfold into fresh broth at $37^{\circ}$, and finally mated after each sample had grown up to $c$. $10^{8}$ bacteria/ml. (at 90, I20 and $150 \mathrm{~min}$. respectively), all showed the same 'plateau' recombination frequency, despite a fourfold difference in the number of generations after development of the effect. It should also be noted that, following the initiation of induction, new donors are generated at a much faster rate than are new bacteria during exponential growth.

\section{Metabolic requirements for development of the effect}

The development of the effect was investigated under various conditions of growth and in the presence of various metabolic inhibitors.

(i) Growth in minimal medium. $\mathrm{F}^{+}$and intermediate male strains grown overnight in, and subcultured to, minimal medium develop the effect with normal kinetics if incubated in the same medium, instead of in broth, after irradiation. In contrast, if broth-grown cells are irradiated and then incubated in minimal medium, supplemented with the required growth factors, the number of recombinants falls about threefold during the first hour, but then rises to many times the initial number during the second hour of incubation. We do not know to what extent the fall during the first hour is due to inability to mate as a result of the inhibition of protein synthesis which follows the 'shift-down' from broth to minimal medium (see Maaløe \& Kjeldgaard, 1966). However, it is clear that recovery of the bacteria from the effects of the 'shift-down' is accompanied by delayed development of the effect.

(ii) Inhibition of protein synthesis. Attempts to judge whether development of the effect is inhibited by withdrawal of a required amino acid were frustrated by the fact that, under these conditions, the ability of male cells to mate falls rapidly to a low value (Hayes, unpublished data). The effects of chloramphenicol were therefore investigated. Preliminary control experiments showed that treatment of $\mathrm{Hfr}$ bacteria with $100 \mu \mathrm{g}$. $/ \mathrm{ml}$. chloramphenicol for $30 \mathrm{~min}$. has little effect on their fertility, so that a study of the action of this drug on the development of the u.v. effect seemed feasible. It turned out, however, that Hfr bacteria which have been irradiated with u.v. light show a more than tenfold diminution of fertility when treated with chloramphenicol under the same conditions, so that it is difficult to appraise the outcome of this type of experiment.

(iii) Deprivation of energy source. Minimal-grown bacteria incubated, after irradiation, in the same medium without glucose, develop almost the full effect. In kinetic experiments under these conditions the total number of recombinants, instead of falling after the peak (Fig. 2), remain constant for the duration of the experiment $(3 \mathrm{hr})$. No increase in viable count occurs throughout this period. It seems reasonable that the development of the effect under these conditions may depend on a residual endogenous energy source. Once produced, the effect fails to decline because this energy source is depleted. No experiments were performed involving deprivation of glucose before irradiation.

Another means of energy deprivation is by the addition of $10^{-3} \mathrm{M}$-dinitrophenol (DNP) to the minimal medium, which inhibits both multiplication and chromosome transfer (Fisher, 1957). This concentration of DNP during the first $30 \mathrm{~min}$. of post- 
irradiation incubation reduced the effect twofold; however, the effect developed normally on a further $30 \mathrm{~min}$. incubation after removal of the DNP.

(iv) Deprivation of thymine. A thymine-requiring mutant of strain w I655. $\mathrm{F}^{+}$, grown in minimal medium + thymine, was irradiated with u.v. light and then incubated in minimal medium without thymine for $30 \mathrm{~min}$. before mating in the presence of thymine. Despite a $50 \%$ fall in the viable population from thymineless death, very nearly the same increase in the number of recombinants occurred as in the control sample, incubated in minimal medium + thymine after irradiation. In the case of u.v.irradiated bacteria, thymineless death starts immediately after incubation, without the lag seen in unirradiated cultures. A further $40 \mathrm{~min}$. of thymine starvation, yielding only 10\% survivors, was also without significant effect on the absolute number of recombinants. It is concluded that a major degree of inhibition of DNA synthesis has no appreciable effect on the development of new donors.

Table 2. The effect of various agents on the total number of recombinants, and on the recombination frequency, generated by $F^{+}$bacteria at different levels of survival

In the experiments with u.v. radiation, Mitomycin C (MC) and X-rays, log. phase, brothgrown $\mathrm{W} \mathrm{I} 655 . \mathrm{F}^{+}$bacteria were used and incubated in broth of $\mathrm{I} \mathrm{hr}$ after treatment, prior to mating with strain $242 . \mathrm{F}^{-}$for $45 \mathrm{~min}$. and plating for pro ${ }^{+}$recombinants. In the case of 5 -bromouracil uptake (BU) and thymine starvation (TS), thymine-requiring $\mathrm{F}^{+}$bacteria were employed and, after treatment, incubated in minimal medium + thymine for one hour before mating. For methylmethansulphonate treatment (MMS) minimal medium was used throughout.

\begin{tabular}{|c|c|c|c|c|c|}
\hline Group & Agent & Dosage & $\begin{array}{c}\text { Percentage } \\
\text { survival }\end{array}$ & $\begin{array}{l}\text { Increase in total } \\
\text { no. recombinants }\end{array}$ & $\begin{array}{l}\text { recombination } \\
\text { frequency }\end{array}$ \\
\hline \multirow[t]{8}{*}{ I } & U.v. & $20 \mathrm{sec}$. & 68 & $\times 16$ & $\times 23.5$ \\
\hline & & $40 \mathrm{sec}$ & 37 & $\times 17 \cdot 5$ & $\times 47$ \\
\hline & $\mathrm{MC}(\mathrm{I} O \gamma / \mathrm{ml})$. & $5 \mathrm{~min}$. & 60 & $\times 4$ & $\times 6.6$ \\
\hline & & $15 \mathrm{~min}$. & 25 & $\times 10$ & $\times 40$ \\
\hline & TS & $60 \mathrm{~min}$. & 83 & $\times 8.4$ & $\times 10$ \\
\hline & & $100 \mathrm{~min}$. & 36 & $\times 5 \cdot 2$ & $\times 13.2$ \\
\hline & & $140 \mathrm{~min}$. & 8 & $\times \quad 1 \cdot 9$ & $\times 24$ \\
\hline & $\mathrm{BU}(40 \gamma / \mathrm{ml})$. & $2 \mathrm{hr}$ & 25 & $\times 3$ & $\times 12$ \\
\hline \multirow[t]{6}{*}{ II } & $\mathrm{X}$-rays $\left(\mathrm{in}_{2}\right.$ ) & $5 \mathrm{~min}$. & 45 & $\times I$ & $\times 2 \cdot 2$ \\
\hline & & $15 \mathrm{~min}$. & 5 & $\times 0.25$ & $\times 5$ \\
\hline & & $25 \mathrm{~min}$. & $0 \cdot \mathbf{I}$ & $\times 0.025$ & $\times 25$ \\
\hline & MMS $(0.025 \mathrm{M})$ & Io $\mathrm{min}$. & 40 & $\times 0.8$ & $\times 2$ \\
\hline & & $20 \mathrm{~min}$. & 18 & $\times 0.6$ & $\times 3.3$ \\
\hline & & $30 \mathrm{~min}$. & 8 & $\times 0.3$ & $\times 3.7$ \\
\hline
\end{tabular}

Induction of the donor state by agents other than u.v. light

We tried to imitate the u.v. effect by using various other agents known to inflict damage on the chromosomal DNA. Although the type of damage produced by each agent is undoubtedly different, we looked for similarity with respect to induction of new donor bacteria in $\mathrm{F}^{+}$and intermediate male populations. The agencies tested were X-rays, Mitomycin C (MC), methylmethansulphonate (MMS), the incorporation of 5 -bromouracil (BU) into the DNA, and deprivation of thymine (TS) in a thyminerequiring mutant. These agencies fall into two clearcut groups with respect to their effect on the total number of recombinants and the recombination frequency, as is 
shown in Table 2. It is clear that the agents in group I produce an increase in the absolute number of recombinants at all survival levels shown, as well as an increase in the recombination frequency. On the contrary, group II agents stimulate no increase in the absolute number of recombinants, although the percentage recombinants among the survivors rises.

\section{The molecular mechanism of the u.v.-induction of the donor state}

From the experiments so far described it is apparent that treatment with u.v. radiation and certain other agents induces the formation of new donor bacteria in $\mathrm{F}^{+}$and intermediate male bacterial populations. From the kinetics of induction and its decay it is evident that the induced donor state differs from the normal Hfr state in not being inheritable. This could theoretically be ascribed either to inability of the induced donor cells to divide, or to an abortive unilinear inheritance of the induced donor state. If the former, more likely, hypothesis is correct, and assuming that chromosome transfer requires an integrated sex factor, it follows that the process of induction leads to chromosomal insertion of the sex factor in such a way that the newly formed structure is capable of genetic transfer but not of replication.

In the last section we pointed out that this new type of donor is induced only by agents belonging to group I (Table 2). Many agents of this type have in common the production of DNA damage which is repaired by a process involving excision of single-stranded fragments which have suffered a lesion, so that acid-soluble nucleotides appear in the medium (Setlow \& Carrier, 1964; Boyce \& Howard-Flander, I964; Boyce, 1966). As a result of this excision, single-stranded gaps are exposed in the chromosomal DNA which are repaired by new DNA synthesis using the interrupted strand as a primer and the intact, complementary strand as a template (Pettijohn \& Hanawalt, 1964).

All the evidence now supports the general hypothesis that chromosome transfer at significant frequency is a consequence of insertion of a circular sex factor into the circular bacterial chromosome by a recombination event in a region of genetic homology between them (review: Scaife, I967). At the molecular level, this homology must be due to similar base sequences on the parental DNA molecules. In order that these sequences may recognize each other so that pairing, which precedes recombination, can occur, the two strands of each DNA molecule must open up in the region of homology. The sequence of bases on each sex factor strand can then pair with the complementary chromosomal strand by hydrogen bonding. Subsequent breakage and reunion of strands presumably occurs so that, finally, both strands of the sex factor DNA are inserted into the continuity of the chromosomal DNA.

When we now reconsider the excision of DNA strands induced by u.v. light, we can regard the exposed single-stranded regions as substituting for the first step in recombination at which the DNA duplex opens. If this exposed strand should happen to possess homology for a region of the sex factor DNA, pairing with the sex factor should be greatly facilitated. On the basis of this supposition we propose a possible model which involves recombination between only a single strand of chromosomal DNA and sex factor DNA, as shown in Fig. 3 .

Excision of a strand of the DNA of the bacterial chromosome in a region of sex factor homology leads to pairing of the complementary sex factor DNA strand (Fig. $3 \mathrm{~B}$ ), followed by breakage and covalent bonding which joins a free end of the excised 
strand to the paired sex factor strand (Fig. $3 \mathrm{C}$ ). This structure, unorthodox as it seems, appears capable of fulfilling the general requirements of the phenomenon we describe. Thus it possesses no obvious barrier to replication initiated in the sex factor continuing along the chromosome, so that transfer may be effected. On the other hand, a second replication of the chromosome, or the completion of a single replication initiated elsewhere than in the sex factor, will be blocked at the sex factor attachment site so that the cell will be inviable.

In view of the plausability of this model, let us examine some predictions which derive from it. Pre-eminent among these are the necessity for single-stranded excision and for recombination, so that the u.v. effect should not develop in $u v r^{-}$mutant bacteria which cannot excise pyrimidine dimers (Howard-Flanders, 1964; van de Putte, van Sluis, van Dillewijn \& Rörsch, 1965), nor in $\mathrm{rec}^{-}$mutants which are unable to mediate genetic recombination (Clark \& Margulies, 1965; Howard Flanders \& Theriot, 1966).
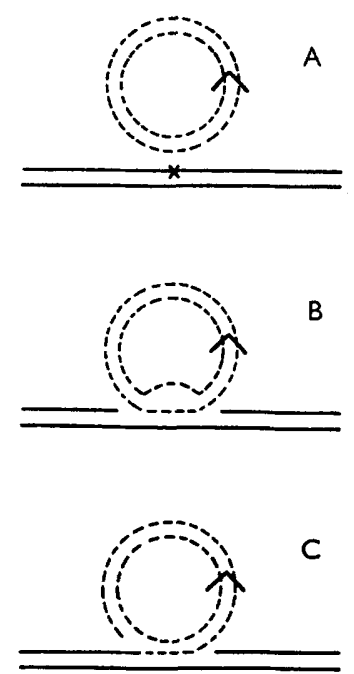

Fig. 3. A molecular model for the mechanism of induction of the donor state by u.v. radiation. The pair of interrupted lines represents the two strands of the sex factor DNA; the arrow indicates the direction of sex factor replication. The pair of continuous lines represents the two strands of chromosomal DNA.

(A) One strand of chromosomal DNA has sustained a u.v. lesion, marked $x$, in a region of sex factor homology. (B) The u.v. lesion, together with part of the adjacent polynucleotide strand, has been excised. The two strands of sex factor DNA have opened up in the region of homology and one has paired with the exposed complementary strand of chromosomal DNA. (C) The paired strand of sex factor DNA has been broken and rejoined to one of the free ends of the excised strand of chromosomal DNA by an act of recombination.

\section{Experiments with $\mathrm{rec}^{+}$and uvr $^{+}$Escherichia coli mutants}

To examine the effect of u.v. irradiation on chromosome transfer by these mutant strains, the rec $\mathrm{c}^{-}$strain $\mathrm{AB} 2463$ and the $u \mathrm{vr}^{-}$strain $\mathrm{AD}$ I 886 were infected with an F-lac ${ }^{+}$ factor by conjugation with w $1655\left(\mathrm{~F}-\mathrm{lac}^{+}\right)$. In addition, the $\mathrm{rec}^{-}$intermediate male derivative was also infected with the colicin factor, colIb, which is known to restore a high degree of u.v. resistance to this strain without affecting its recombination defect (Mr E. M. Moody, personal communication); the $u v r^{-}$derivative was similarly 
infected with colIb, but here no protection was observed. In general, doses of u.v. light were chosen so as to yield both survival levels and absolute doses of irradiation comparable to those found to increase the total number of recombinants with normal intermediate males (cf. Fig. I). The results are shown in Table 3.

It can be seen that in no case did any increase in the absolute number of recombinants occur. One of a new class of recombination-deficient mutants JW-AI(F-lac- $)$, isolated by $\mathrm{Mr} \mathrm{J}$. Walpole, which retains almost the full wild-type degree of resistance to u.v. light, gave no recombinants with the $\mathrm{F}^{-}$strain 242 , nor was it induced to do so by u.v. irradiation.

Table 3. The effect of u.v. irradiation on the fertility of intermediate male, mutant strains unable to mediate recombination ( $\left.\mathrm{rec}^{-}\right)$or to excise pyrimidine dimers $\left(\mathrm{uvr}^{-}\right)$

In all these crosses strain w I655. $\mathrm{F}^{-}\left(\right.$met $\left.^{-}\right)$was used as female, the inheritance of the male chromosomal marker, $\mathrm{met}^{+}$, being selected.

\begin{tabular}{|c|c|c|c|c|}
\hline Strain & $\begin{array}{l}\text { U.v. dosage } \\
\text { (sec.) }\end{array}$ & $\begin{array}{c}\text { Percentage } \\
\text { survival }\end{array}$ & $\begin{array}{l}\text { Increase in total } \\
\text { no. recombinants }\end{array}$ & $\begin{array}{l}\text { Increase in recom- } \\
\text { bination frequency }\end{array}$ \\
\hline $\operatorname{rec}^{+} u v r^{+}\left(\mathrm{F}-\operatorname{lac}^{+}\right)$ & 20 & 35 & $\times 5$ & $\times 12$ \\
\hline $\operatorname{rec}^{-}\left(\mathrm{F}-l a c^{+}\right)$ & 5 & 4 & $\times 0.08$ & $\times 2$ \\
\hline $\operatorname{rec}^{-}(\operatorname{collb})\left(\mathrm{F}-\mathrm{lac}^{+}\right)$ & 20 & 42 & $\times 0.9$ & $\times 2$ \\
\hline$u v r^{-}\left(\mathrm{F}-\operatorname{lac}^{+}\right)$ & $\begin{array}{r}3 \\
6 \\
12\end{array}$ & $\begin{array}{l}60 \\
4 \\
0.4\end{array}$ & $\begin{array}{l}\times 1 \cdot 0 \\
\times 1 \cdot 0 \\
\times 0.25\end{array}$ & $\begin{array}{l}\times 1 \cdot 7 \\
\times 25 \\
\times 63\end{array}$ \\
\hline $\operatorname{uvr}^{-}(\operatorname{colllb})\left(\mathrm{F}-\mathrm{lac}^{+}\right)$ & $\begin{array}{r}3 \\
6 \\
12\end{array}$ & $\begin{array}{l}60 \\
10 \\
0.6\end{array}$ & $\begin{array}{r}\times I .0 \\
\times I .0 \\
\times 0.4\end{array}$ & $\begin{array}{l}\times 1 \cdot 7 \\
\times 10 \\
\times 68\end{array}$ \\
\hline
\end{tabular}

The frequency of recombinants given by the unirradiated $\mathrm{rec}^{-}\left(\mathrm{F}-\mathrm{lac}^{+}\right)$strain was 150 times lower than that of the control rec $\left(\mathrm{F}-\mathrm{lac}^{+}\right)$donor. The $\mathrm{rec}^{-}\left(\mathrm{F}-\mathrm{lac}^{+}\right)$and $\mathrm{uvr}^{-}\left(\mathrm{F}-\mathrm{lac}^{+}\right)$strains all behaved as normal intermediate males so far as the transfer of the F-lac ${ }^{+}$factor was concerned. The u.v. lamps used in the experiments involving $\mathrm{rec}^{-}$and $u v r^{-}$strains were not the same.

A striking feature of the experiments involving the $u v r^{-}$donor strains is the very big increase in recombination frequency with u.v. dosage. It is obvious that in these strains, unlike $u v r^{+}$strains, radiation damage which kills a high proportion of bacteria does not prevent chromosome transfer. A comparison of the proportionate reduction in the total number of recombinants in $u v r^{-}\left(\mathrm{F}-\mathrm{lac}^{+}\right)$and $u v r^{+} \mathrm{Hfr}$ crosses shows that these are similar for any given absolute u.v. dose; that is, the dosage at which the total number of recombinants begins to fall is about the same in the two crosses, despite the vastly higher sensitivity of the $u v r^{-}$donor to lethal u.v. damage. Thus the rise in the recombinant frequency in the case of the $u v r^{-}$donor, as compared with its constancy with the Hfr donor (Fig. I C), must be ascribed to the fact that inability to excise pyrimidine dimers does not interfere with chromosome transfer. This view is confirmed by the finding that a $u v r^{-}$Hfr strain, made by phage P I co-transduction of a defective $u v r B$ locus with the $\mathrm{gal}^{+}$gene, from strain AB I885 to a $\mathrm{gal}^{-} \mathrm{Hfr}$. H strain, displays the same marked rise in recombination frequency with dosage; as before, the total number of recombinants remains constant with increasing dosage up to the dose required to reduce the number of recombinants in the control $u v r^{+} \mathrm{Hfr}$ cross, although the proportion of $u v r^{-}$survivors at this dose is very small. This implies that 
inhibition of chromosome transfer by u.v. light is due to some effect of radiation, such as cross-linking of DNA strands, other than dimer formation.

The need for excision is substantiated by the finding that development of the u.v. effect in irradiated $u v r^{+} \mathrm{F}^{+}$bacteria is inhibited by acriflavine, which prevents pyrimidine dimer excision (Harm, 1967; Setlow, 1966). Moreover, the effect is reversed by photoreactivation which acts specifically by uncoupling pyrimidine dimers (Rupert, I96I; Setlow, Carrier \& Bollum, 1965). All these findings are fully compatible with the hypothesis that the u.v. effect requires both excision of damaged DNA strands as well as an act of genetic recombination, even though they do not offer direct proof of this hypothesis.

\section{The effect of $X$-rays and of methylmethansulphonate (MMS) on the behaviour of $u . v .-$ induced donor bacteria}

In the model we have proposed (Fig. 3) the sex factor and the chromosome are connected by a single DNA strand, in distinction to normal chromosome donors. Despite the presumed shortness of such a single-stranded connection, we thought it possible that transfer by such a structure might prove more sensitive to the action of agents such as X-rays and MMS which are supposed to produce single-stranded breaks in DNA (see Marcovitch, 196I; Brooks \& Lawley, I96I; Strauss \& Wahl, 1964; Wahl, 1965), although in the case of MMS there is evidence that part, at least, of its effect is subject to a repair process based on excision (Strauss, Reiter \& Searashi, I966; Reiter, Strauss, Robbins \& Marone, 1967).

To test this possibility, cultures of $\mathrm{F}^{+}$bacteria were irradiated with u.v. light and incubated in broth for I hr in order to induce an overwhelming majority of new donors. The bacteria were then treated for different times with either X-rays or 0.025 M-MMS, and finally assayed for viability and ability to generate recombinants in crosses with female bacteria. The results were compared with those obtained with unirradiated, but otherwise similarly treated, control bacteria. Out of two experiments with MMS and three with X-rays, all gave consistent results in that the absolute number of u.v.induced recombinants decreased at about twice the rate of those generated by bacteria unexposed to u.v. radiation. In contrast, the survival curves of the irradiated and unirradiated bacterial populations as a whole, as a function of dose of X-rays and MMS, were not significantly different. Moreover, in control experiments assessing the effects of MMS on Hfr bacteria, irradiated and unirradiated bacteria behaved similarly with respect both to survival and to the number of recombinants generated. Finally, an equivalent secondary irradiation with u.v. light, instead of with $\mathrm{X}$-rays, resulted in a further increase in the total number of recombinants instead of in a fall.

In the case of X-rays, the relative decrease in the capacity for transfer of u.v.-induced donors was apparent only when the proportion of survivors exceeded about $25 \%$.

\section{DISCUSSION}

The evidence we have presented makes it probable that the induction of donors by u.v. radiation and other agents requires recombination as well as the excision of damaged DNA strands. These induced donors differ from normal donors in two respects; the donor state in them is not inheritable, probably due to the formation of a genetic structure which can lead to transfer but cannot replicate, while the ability of the donor 
bacteria to transfer their chromosome appears to be more sensitive than normal to the action of X-rays and MMS, though not of u.v. radiation. There is now little doubt that chromosome transfer by Hfr and intermediate male bacteria, and probably also by $\mathrm{F}^{+}$bacteria, normally depends on the double-stranded insertion of the sex factor DNA into that of the chromosome. If a physical continuity between sex factor and chromosome is indeed essential, it is difficult to envisage an alternative to the singlestranded insertion which can explain the experimental findings. A possible hypothesis that the majority of double-stranded normal insertions are lethal, due to disruption of some vital chromosomal function, and that the effect of u.v. irradiation is simply to increase the frequency of these normal events, does not account for absence of the effect in $u v r^{-}$mutants, since there is no difference between the number of recombinants generated by unirradiated $\mathrm{F}^{+} . u v r^{+}$and $\mathrm{F}^{+} . u v r^{-}$populations. Thus, faute de mieux, we have proposed the model shown in Fig. 3.

We have seen that the total number of recombinants generated by $\mathrm{F}^{+}$or intermediate male populations rises with increasing dosage up to about $30 \%$ survival, after which the number of recombinants begins to fall at about the same rate as the survivors (Fig. I). If our hypothesis is correct, that the u.v. induction of new donors is due to a facilitation of pairing between sex factor and chromosome as a result of strand excision, it follows that the effect will reach its peak at a dose which promotes the maximal degree of excision compatible with chromosome repair. This would yield just the type of dose-effect curve found.

The twofold greater sensitivity of u.v.-induced donors to relatively low doses of $\mathrm{X}$-rays or MMS, as compared with normal donors, is hard to account for, even if we take the simplest view that these agents act by producing single-strand breaks in DNA. It is, however, consistent with our model since this possesses a single-stranded connection between sex factor and chromosome which should be very vulnerable to agents that produce single-strand breaks.

We wish to thank Miss Carole Atkinson for invaluable technical assistance in those studies made at the University of Sussex, and Mr J. Walpole for providing his radiationresistant, recombination-defective strain. Z. Evenchik acknowledges his indebtedness to the B. de Rothschild Foundation and to the European Molecular Biology Organization for the financial support which made possible his participation in this research.

\section{REFERENCES}

BOYCE, R. P. (1966). Production of additional sites of DNA breakdown in bromouracil-containing Escherichia coli exposed to UV. Nature, Lond. 209, 688.

BOyCE, R. P. \& Howard-Flanders, P. (I964). Release of ultraviolet light-induced thymine dimers from DNA in E. coli K I2. Proc. natn. Acad. Sci. U.S.A. 51, 293.

Broda, P. (1967). The formation of Hfr strains in Escherichia coli $\mathrm{K}$ I2. Genet. Res., Camb. 9, 35.

Broda, P., Beckwith, J. R. \& SCAIFE, J. (1964). The characterisation of a new type of F-prime factor in Escherichia coli $\mathrm{K}$ 12. Genet. Res., Camb. 5, 489.

Brooks, P. \& LAWley, P. D. (196I). The reaction of mono- and di-functional alkylating agents with nucleic acids. Biochem. J. 80, 496.

Cavalli-Sforza, L. L. \& Jinks, J. L. (1956). Studies on the genetic system of E. coli K I2. J. Genet. $54,87$.

Clark, A. J. \& MARgulies, A. D. (1965). Isolation and characterisation of recombination deficient mutants of E. coli $\mathrm{K}$ I2. Proc. natn. Acad. Sci., U.S.A. 53, $45 \mathrm{I}$. 
Clowes, R. C. \& Rowley, C. (1954). Some observations on linkage effects in genetic recombination in E. coli $\mathrm{K}$ 12. J. gen. Microbiol. $\mathbf{1 1}, 250$.

FISHER, K. W. (1957). The nature of the endergonic processes in conjugation in Escherichia coli K I2. J. gen. Microbiol. 16, I36.

HAAS, F., Wyss, O. \& STONE, W. S. (1948). The effect of irradiation on recombination in Escherichia coli. Proc. natn. Acad. Sci., U.S.A. 34, 229.

HARM, W. (1967). Differential effects of acriflavine and caffeine on various ultraviolet irradiated Escherichia coli strains and T I phage. Mutation Res. 4, 93.

HAYES, W. (1952). Genetic recombination in Bact. coli $\mathrm{X}$ 12: analysis of the stimulating effect of ultraviolet light. Nature, Lond. 169, 1017.

HaYes, W. (1953). The mechanism of genetic recombination in Escherichia coli. Cold Spr. Harb. Symp. quant. Biol. 18, 75 .

HAYES, W. (1960). The bacterial chromosome. Symp. Soc. gen. Microbiol. ro, 12.

Howard-Flanders, P. (1964). In discussion of Setlow, R. B. (1964). Physical changes and mutagenesis. J. cell. comp. Physiol. 64 (Suppl. I), 5 I.

HowARD-Flanders, P. \& THERIOT, L. (1962). A method for selecting radiation-sensitive mutants of Escherichia coli. Genetics 47, 1219.

Howard-Flanders, P. \& THERIOT, L. (1966). Mutants of Escherichia coli $\mathrm{K}$ I2 defective in DNA repair and in genetic recombination. Genetics 53, I 137.

Howard-Flanders, P., Boyce, R. P. \& Theriot, L. (I966). Three loci in Escherichia coli $\mathrm{K}$ I 2 that control the excision of pyrimidine dimers and certain other mutagen products from DNA. Genetics 53, II 19.

LeDERBERG, E. M. \& Lederberg, J. (I953). Genetic studies of lysogenicity in interstrain crosses of E. coli. Genetics 38, $5 \mathrm{I}$.

LenNox, E. S. (1955). Transduction of linked genetic characters of the host by bacteriophage PI. Virology $\mathbf{1}, 190$.

MaAløe, O. \& KJeldgaArd, N. O. (1966). Control of Macromolecular Synthesis. New York and Amsterdam: W. A. Benjamin, Inc.

Marcovitch, H. (196I). Do X-rays produce chromosome breakage in Escherichia coli $\mathrm{K}$ I2? J. cell. comp. Physiol. 58 (Suppl. I), I07.

Pettijohn, D. \& Hanawalt, P. (I964). Evidence for repair-replication of ultraviolet damaged DNA in bacteria. J. molec. Biol. 9, 395.

Reiter, H., Strauss, B., Robbins, M. \& Marone, R. (I967). Nature of the repair of methyl methane sulphonate-induced damage in B. subtilis. J. Bact. 93, 1056.

RUPERT, C. S. (I961). Repair of ultraviolet damage in cellular DNA. J. cell. comp. Physiol. 58 (Suppl. I), 57.

SCAIfE, J. (1967). Episomes. A. Rev. Microbiol. 21, 60I.

SCAIFE, J. \& Gross, J. D. (I963). The mechanism of chromosome mobilisation by an F-prime factor in Escherichia coli $\mathrm{K}$ 12. Genet. Res. Camb. 4, 328.

SetLow, J. K. (1966). The molecular basis of biological effects of ultraviolet irradiation and photoreactivation. In Current Topics in Radiation Research (Ed. by M. Ebert and A. Howard), vol. II. Amsterdam: North Holland Publishing Co.

Setlow, R. B. \& CARRIER, W. L. (1964). The disappearance of thymine dimers from DNA: an error correcting mechanism. Proc. natn. Acad. Sci. U.S.A. 51, 226.

Setlow, R., Carrier, W. \& Bollum, F. (I965). Pyrimidine dimers in UV-irradiated dI:dC. Proc. natn. Acad. Sci. U.S.A. 53, I I I .

STACEY, K. A. \& Simson, E. (1965). Improved method for the isolation of thymine-requiring mutants of Escherichia coli. J. Bact. 90, 554.

STRAUSs, B. S. \& WAHL, R. (1964). The presence of breaks in DNA of B. subtilis treated in vivo with the alkylating agent, methyl methane sulphonate. Biochim. biophys. Acta Ir6, I 26.

Strauss, B., Reiter, H. \& Searashi, T. (1966). Recovery from ultraviolet and alkylating agentinduced damage in Bacillus subtilis. Radiation Res. (Suppl. 6), 201.

Van de Putte, P., Van Sluis, C. A., Van Dillewijn, J. \& Rörsch, A. (1965). The location of genes controlling radiation sensitivity in Escherichia coli. Mutation Res. 2, 97.

WAHL, R. (1965). Detection of single strand breaks in DNA alkylated in vitro. Fedn. Proc., Fedn. Am. Ass. biol. Soc. 24, 226. 